\title{
Prevalence and determinants of undernutrition among school children of Ethiopia: a systematic review and meta-analysis
}

Tamirat Hailegebreil ( $\nabla$ tamiratbdu@gmail.com )

Research article

Keywords: stunting, wasting, thinness, undernutrition, systematic review, meta-analysis

Posted Date: August 23rd, 2019

DOI: https://doi.org/10.21203/rs.2.13434/v1

License: (c) (i) This work is licensed under a Creative Commons Attribution 4.0 International License.

Read Full License 


\section{Abstract}

Background: Ethiopia is the second populous countries in Africa where millions of children are affected by malnutrition. Several original works are available online about child malnutrition in Ethiopia. The aim of this study was to summarize the existing epidemiological data on undernutrition and possible determinants among school children in Ethiopia.

Methods: We conducted a systematic review using open access articles which report prevalence of stunting and wasting/thinness from PubMed Central, Scopus and Science direct. From 358 articles accessed online, 39 of them were eligible for this meta-analysis. The heterogeneities among studies were evaluated using $\mathrm{I} 2$ test and the pooled prevalence was calculated using a random effect model.

Results: A total of 24, 716 school children were included in 39 eligible articles for this meta-analysis. The pooled prevalence of stunting and wasting/thinness among school children in Ethiopia were 23.1\% (95\% Cl: $19.0-27.0 \%)$ and $22 \%(95 \% \mathrm{Cl}: 17 \%-26 \%)$, respectively. The risk of stunting was increased among the student with meal frequency $\leq 3$ times a day $(\mathrm{OR}=3.02,95 \% \mathrm{Cl}: 1.90-4.14)$, age $>10$ years $(\mathrm{OR}=2.16$, $95 \% \mathrm{Cl}: 1.47-2.85)$ and family size $\geq 5(\mathrm{OR}=1.88,95 \% \mathrm{Cl}: 1.40-2.35)$. Similarly, the risk of wasting/thinness was increased with male sex $(\mathrm{OR}=2.06,95 \% \mathrm{Cl}: 1.54-2.58)$, low family income (OR= $2.16,95 \% \mathrm{Cl}: 1.30-3.01)$ and age $>10$ years $(\mathrm{OR}=1.78,95 \% \mathrm{Cl}: 0.74-2.82)$. High heterogeneity about the prevalence of stunting and wasting/thinness was observed among studies included in this meta-analysis $(12>98.6)$.

Conclusions: This study showed that stunting and wasting/thinness are common nutritional problems in school children in Ethiopia. Large family size, male sex and age above 10 years were consistently associated with stunting and wasting/thinness in children. The finding of this study highlights the importance of new strategies to reduce undernutrition in Ethiopia.

Keywords: stunting, wasting, thinness, undernutrition, systematic review, meta-analysis

\section{Introduction}

Undernutrition is the inability of obtaining right amount of nutrients that fulfill the body demand for optimum function. It is one of the major causes of child morbidity and mortality in developing countries. Undernutrition is classified into stunting, underweight, wasting/thinness and deficiency of vitamins and minerals [1]. Stunting is a chronic form of undernutrition which reflects previous failure of optimum growth while wasting/thinness is an acute form of malnutrition that indicates recent food shortage [2]. Underweight indicates a combination of acute and chronic malnutrition at a time [1].

According to $\mathrm{WHO}$, stunting and wasting affect 150 million and 52 million children, respectively [3]. The problem of undernutrition is severe in Africa and Asia, where more than $90 \%$ of stunted and underweight preschool children are living in the two regions $[4,5]$. The global prevalence of stunting and wasting among preschool children were $36 \%$ and $8.5 \%$, respectively in Africa in 2011[4]. Similarly, stunting and 
thinness affecting 20 - 30\% and 35\% school children in Africa, respectively [6]. Despite the millennium development goal targeting reduction of undernutrition, the problem is still high in sub-Saharan African countries. As stated in the 2015 MDG report, $23 \%$ of children in sub-Saharan Africa are undernourished [7]. The prevalence of undernutrition above $20 \%$ is considered as a public health importance [8].

Therefore, undernutrition is still one of the major challenges for children livening in African countries. Chronic undernutrition further leads to serious problem in child health, physical growth and school performance.

Child malnutrition is one of the serious problems among children in Ethiopia, where more than $55 \%$ of the population are below the age of 19 years. According to the 2007 population census, school aged children (7-18 years of age) accounts for $34.3 \%$ of the total populations of Ethiopia [9]. In line with this, the 2008 national nutritional survey indicated that $22.3 \%$ and $23.1 \%$ of school children were stunted and thinned, respectively [10]. The number of published articles on the prevalence of undernutrition and possible risk factors in the country is significantly increased since the 2008 national survey. However, there is a huge discrepancy about the prevalence of undernutrition and their potential risk factors among published studies. To my best knowledge, there were no summarized data on the prevalence undernutrition and potential determinants among school children in Ethiopia. Therefore, this systematic review and metaanalysis aimed to summarize online available published studies on the prevalence of undernutrition and possible determinant factors in Ethiopia.

\section{Methods}

\section{Children age category in Ethiopia}

This study is conducted in Ethiopia, which is the second populous country in Africa with an estimated population of 105 million and an area coverage of $1,104,300 \mathrm{~km}^{2}$. Out of the total population, $55.6 \%$ of them are children below the age of 19 years. Children are supposed to enroll in primary school at the age of 7 years and spent an average of 12 years at school in Ethiopia. The first cycle starts from grade 1 to 4 (7-10 years), second cycle from grade 5 to 10 (11-16 years) and preparatory school in grade $11 \& 12$ (17-18 years). Thus, school aged children in Ethiopia is ranges from 7 to 18 years of age. Most nutritional studies in Ethiopia were conducted at primary and secondary school children. Therefore, all studies included in this systematic review and meta-analysis was conducted on primary and secondary school children.

\section{Anthropometric indicators}

Anthropometric indicators namely stunting, underweight, wasting or thinness were used based on NCHS/WHO definition [11]. The Z-score value below minus two standard deviation (-2 SD) from $\mathrm{NCHS} / \mathrm{WHO}$ reference population was considered to determine undernutrition. Children were labeled as stunted (height-for age $<-2$ SD), underweight (weight-for-age $<-2$ SD) and wasted or thinned (weight- 
for-height or body mass index (BMI)-for-age <-2 SD) [2,11]. Weight-for-height is applicable for children below the age of 10 years to determine wasting while BMI-for-age is used for children from 5-19 years of age to assess children thinness [11]. Therefore, all articles selected and included in this meta-analysis were based on NCHS/WHO growth reference parameters.

\section{Search strategies}

Relevant literatures were systematically searched from three online databases (PubMed Central, Scopus and Science Direct) using the following key words: "Ethiopia", "undernurition", "malnutrition", "acute malnutrition", "chronic malnutrition", "stunting", "wasting", and "thinness". Searching of relevant articles used for this meta-analysis was conducted from December 2018 to January 2019. The systematic review and selection of relevant literatures were conducted according to the PRISMA (Preferred Reporting Items for Systematic Reviews and Meta-analysis) guidelines [12] (Additional file 1: Table S1).

\section{Selection, inclusion and exclusion criteria}

Original articles reporting the prevalence of undernutrition (stunting and wasting/thinness) and possible predictors in school children in Ethiopia were selected for this study. Articles containing the prevalence of stunting, wasting/thinness and associated risk factors along with age range of students, total study population and study area were included for this systematic review and meta-analysis. All articles included in this meta-analysis were written in English and published between 2009 and 2018. Nutritional studies conducted on preschool children, community based study, specific groups (only female or male students), patients, reports form review paper or conference abstract were excluded from this metaanalysis.

\section{Methods of data extraction}

Literatures were extracted from online databases using data extraction protocol developed by the author. The data extraction protocol consists of sample size, method of participant selection, age group, study design, study regions, year of publication, prevalence of stunting and wasting/thinness and risk factors of undernutrition. The summarized information was used to determine the overall prevalence as well as major determinants of undernutrition among school children in Ethiopia.

\section{Quality assessment}

The quality of individual studies included in this meta-analysis was assessed using STROBE (Strengthening the Reporting of Observational studies in Epidemiology) checklist [13]. The checklist is used to assess internal validity (measurement biased) and external validity (selection biased) of studies 
included in this-meta-analysis. Among the 22 STROBE items, we select 8 quality assessment parameters namely sample size, sampling methodology, response rate, statistical analysis, ethical consideration, outcome measure, confounding and study limitation (Additional file 2: Table S2). Studies were assigned either 1 (if the criterion was met) or 0 (if the criterion was not met). The overall quality score was determined by adding the assigned number for each parameter and classified as low quality $(\leq 3)$, medium quality $(4-6)$ or high quality $(\geq 7)$ as described elsewhere [5].

\section{Statistical analysis}

The prevalence of undernutrition (stunting and wasting/thinness)was calculated by dividing the number of positive subjects by the total study participants. The heterogeneity among studies used for this metaanalysis was assessed using $\mathrm{I}^{2}$ test [14]. Heterogeneity is defined as the degree of variability across studies. The heterogeneity of the studies were classified as low, moderate and high based on the $\mathrm{I}^{2}$ value less than $25 \%, 25-50 \%$ and above $50 \%$, respectively [15]. Considerable heterogeneity was observed among the studies included in the meta-analysis. Thus, a random-effect model at $95 \% \mathrm{Cl}$ was used for estimating of the overall effect. The meta-analysis was conducted using Stata software (version 14, STATA Corp College Station, TX), where $p<0.05$ was considered as statistical significant.

\section{Results}

\section{Characteristics of the eligible studies}

A total of 358 studies about undrnutrition in school children in Ethiopia were available in the selected online databases. Out of those articles, 141 articles were excluded based on duplication while 112 articles were excluded during title and abstract screening. The remaining 105 full text articles were assessed for their eligibility. Of those articles, 66 were excluded from the analysis based on specific exclusion criteria (Fig. 1). The remaining 39 articles were included for this systematic review and meta-analysis. The detailed characteristic of eligible articles included in this meta-analysis was presented in Table 1.

The 39 eligible original articles were obtained from 5 regions (Amhara, Oromia, Somali, South Nations and Nationalities Peoples (SNNP) and Tigray) and 1 city administration (Addis Ababa). These regions and city administration accounted for more than 95\% of the total population of Ethiopia. A total of 24, 716 school children were included in the 39 eligible articles [16-54]. Among these eligible articles, 26 contain data for both stunting and 
wasting/thinness while 13 articles addressing either stunting or wasting/thinness. Therefore, 38 articles and 27 articles were used for the analysis of stunting and wasting/thinness, respectively. All studies included in this meta-analysis were conducted on school children with a minimum age of 4 years and the upper limit was not mentioned in few studies.

\section{Quality assessment}

The overall quality assessment of each article included in this meta-analysis was moderate to high quality score; 7 studies (17.9\%) with moderate quality score while 32 studies (82.1\%) with high quality score (Additional file 3: Table S3).

Prevalence of stunting among school children in Ethiopia

The pooled prevalence of stunting was 23.1\% (95\% CI, 19.0 - 27.0\%) among school children in Ethiopia (Table 2 and Fig. 2). The highest pooled prevalence of stunting was 29.5\% (95\% CI, 27.6-32.5\%), which was observed from Tigray region while the lowest prevalence of stunting was 12.9\% (95\% CI, 8.9\% - 16.9\%) obtained from Oromia region (Table 2). A single study was available from the Somali region that indicate low prevalence of stunting but not fair to compare with other regions based on a single finding.

Prevalence of thinness/wasting among school children in Ethiopia

The pooled prevalence of thinness/wasting was $22 \%$ (95\% CI, 17\% - 26\%) among school children in Ethiopia (Table 2 and Fig. 3). The overall prevalence of wasting/thinness was higher in Tigray region, 39.9\% (95\% CI, 32.1\% - 47.8\%), followed by Amhara region, 22.9\% (95\% CI, 21.8\% - 24.1\%) while lower pooled prevalence was obtained from Oromia region, $14.1 \%$ (95\% CI, $12.8 \%-15.4 \%$ ) (Table 2).

\section{Associated factors of stunting among school children in Ethiopia}


We have reviewed and analyzed potential determinants of stunting among school children from 21 eligible articles in Ethiopia. Age and sex of the students, family size, meal frequency, mother education, rural residency and presence of parasitic infections were associated with stunting of school children in Ethiopia (Fig 4). The pooled results of 14 studies $[19,21,24,27,28,35,36,38,39,41,45-47,53]$ showed that students above ten years of age were 2.16 times more likely to be stunted than students below ten years of age $(\mathrm{OR}=2.16,95 \% \mathrm{CI}: 1.47-2.85)$ (Fig. 4a). The pooled results of 5 studies [17, 19-21, 38] showed that students with meal frequency at most three times a day were 3.02 times more likely to be stunted as compared to students with meal frequency more than three times a day $(\mathrm{OR}=3.02,95 \% \mathrm{CI}: 1.90-4.14)($ Fig. 4b) .

The pooled effect size of five studies $[23,28,38,39,46]$ showed that students with larger family size 1.88 times more likely develop stunting than students with small family size (OR $=1.88,95 \%$ CI: 1.40-2.35) (Fig. 4c). The pooled results of six studies [19, 20, 34, 39, 45, 53] revealed that male students were 1.74 times more stunted than female counterparts (OR $=1.74,95 \%$ CI: 1.36-2.12) (Fig.4d). The pooled effect size of seven studies [21, 28, 35,

$36,39,49,53$ ] indicated that students from rural residency were 1.59 more likely stunted than students from urban areas (OR $=1.59,95 \%$ CI: 0.82-2.36) (Fig. 4e). Similarly, the pooled results of five studies [17, 35, 41-43] indicated that students infected with parasite organism were 1.48 times more likely develop stunting than students without parasitic infection (OR $=1.48,95 \% \mathrm{CI}: 0.40-2.56)$ (Fig. 4f).

\section{Associated factors of thinness/wasting among school children in Ethiopia}

We have reviewed and analyzed potential determinants of thinness/wasting among school children in Ethiopia from 13 eligible articles. Sex of students, age of students, family size, presence of parasitic infections and family income were associated with thinness/wasting among school children in Ethiopia (Fig. 5). The pooled results of six studies [34, 47, 49, 50, $53,54]$ revealed that male students were 2 times more likely to be thinned/wasted than 
female counterparts ( $\mathrm{OR}=2.06,95 \% \mathrm{CI}: 1.54-2.58)$ (Fig.5a). Based on the pooled results of three studies $[19,38,41]$, students living with a low family income were about 2 times more likely to be thinned/wasted than students living with better income family ( $\mathrm{OR}=2.16$, 95\% CI 1.30-3.01) (Fig. 5b)

The pooled results of five studies [24, 36, 47, 50,53] revealed that students above 10 years of age were 1.78 times more likely to be thinned/wasted than students below ten years of age (OR $=1.78,95 \% \mathrm{CI}: 0.74$ - 2.82) (Fig.5c). The pooled effect size of four studies [20, 24, 38,41 ] showed that students with family size above five were 1.72 times more likely to be thinned/wasted as compared with students living with a lower family size (OR $=1.72,95 \%$ CI: 0.98 - 2.47) (Fig. 5d).

\section{Discussion}

Child malnutrition is one of the major global problems that affect millions of children worldwide. The problem is severe in developing regions particularly in sub-Saharan Africa and South Asia where more than $20 \%$ of children are affected by undernutrition [55]. Epidemiological studies on undernutrition are essential to assess the prevalence of undernutrition, outcome of previous intervention programs as well as to design alternative strategies by policy makers. In line with this, several epidemiological data are available online on the prevalence of undernutrition and possible risk factors in Ethiopia. To the best of my knowledge, this is the first systematic review and meta-analysis on undernutrition and possible determinants among school children in Ethiopia.

The pooled prevalence of stunting and wasting/thinness observed in the present study is nearly similar to the result of 2008 national survey [10]. This indicates there is no observable change in the last ten years, despite coordinated efforts to reduce the burden of undernutrition in the country. The Ethiopian government and other stockholders are working on food supplementation through school feeding programs as of 2005 in selected schools. School feeding programs are known to bring positive impact on student's school attendance, academic performance as well as physical growth [56]. However, there is no 
apparent change observed on the prevalence of undernutrition in school children in the country. A lot of works need to be done in the country to reduce the burden of stunting and thinness in school children.

The overall prevalence of stunting among school children in the present study was similar to $22.3 \%$ reported in the 2008 national survey in Ethiopia [10], 22\% from African countries average [6] and 21.7\% among young adolescents in Africa [57]. However, the pooled prevalence of stunting in this study was lower than 35\% reported in a meta-analysis from school children in Karnatake, India [58] and 60\% from Bangladesh [59]. All these data showed that undernutrition is significantly high in Africa and South Asia. Despite the millennium development goal designed to reduce the prevalence of stunting, the problem is still remains high in sub-Saharan Africa and South Asia.

The pooled prevalence of thinness/wasting among school children in Ethiopia was similar to that of the 2008 national survey [10]. However, the present finding was low as compared with 36\% reported from a meta-analysis in African [6] and 28\% from India [58]. The high prevalence of thinness and wasting are linked with low family income, which is still a problem in many Ethiopians. Wasting and thinness are an acute form of malnutrition directly associated with family income, which determine the meal frequency as well as the diversity of diet. The government of Ethiopia needs to improve the living standard of the population particularly low income earners.

We reviewed and analyzed risk factors associated with stunting and wasting/thinness of school children addressed by selected articles for this meta-analysis. Identification of major risk factors of undernutrition is essential to design cost effective intervention strategies to improve the health and growth related problems in children. The risks of developing childhood stunting and wasting/thinness were consistently associated with male sex, age above 10 years and living with a larger family size (above five). The contribution of these risk factors to stunting and wasting/thinness were also reported in a meta-analysis from other African countries [5]. 
The risk of developing stunting was higher among children taking meal at most three times a day compared to their counterparts. It is clear that meal frequency is directly associated with family income. Children living in area where problems of food shortage or low family income, they have higher chance of being stunted and underweight [60]. The levels of family income dictate the provision of balanced diet as well as frequency of meal to their children. Long-term exposure for food shortage an early stage of child leads to chronic malnutrition namely stunting. The level of meal frequency at early childhood play vital role for their physical growth and development.

This study revealed that the risk of stunting and wasting/thinness was higher among male children compared with female counterparts. This result is in line with several studies in sub-Saharan Africa $[5,57,61,62]$. This variation might be associated with differences in physical activity between male and female children in the region. In most sub-Saharan African countries male children help their parents through involvement in energy demanding on-farm and off-farm activities. In addition, males children are more physically active than their female counterpart particularly during child hood [63]. As a result, male children may lose their energy needed for normal growth and other physiological activities that may leads to stunting or thinness. The problem is more severe if this energy loss is accompanying with low meal frequency and minimum diet.

The risk of stunting and wasting/thinness was higher among student above 10 years of age compared with lower age groups, which is in line with a meta-analysis reported from Iran [60] and sub-Saharan Africa [5]. Higher risk of stunting was reported from boys than girls in many African countries include Tanzania [64], Burkina Faso [65] and Uganda [62]. In many African countries, older age children particularly males are involved in energy demanding on-farm activities. Low meal frequencies accompanied with several outdoor activities make male and older children vulnerable for undernutrition especially for stunting and thinness.

There was a remarkable difference in undernutrition between children living within small and larger family size. The odd of being stunted and wasted/thinned was higher in students 
living with a larger family size than those living with a small family size. The contribution of large family size and low income to childhood undernutrition were reported from in Pakistan [66] and sub-Saharan Africa [5]. Children living within a large family size are exposed to nutritional related problems due to shortage adequate diet, poor living and health conditions. Ethiopia is one of the sub-Saharan African countries known in large family size, which predispose children to nutritional related problems.

The presence of parasitic infection and rural residency were increased the risk of stunting among school children in Ethiopia. Chronic parasitic infection particularly helminths are contributing for childhood undernutrition by competing for the available limited nutrients. Conversely, malnourished children are susceptible for parasitic infections, which further aggravate the level of undernutrition. The positive associations of soil transmitted, and undernutrition was reported elsewhere [67-69]. Children living in rural areas are easily exposed for parasitic infection due to high level of environmental sanitation and poor personal hygiene. Therefore, both rural residency and parasitic infections are contributing factors to nutritional related problems in school children in Ethiopia.

\section{Significance/contribution}

Exposures of undernutrition during childhood are affecting their health, physical growth, mental development, work capacity and quality of life during the entire lifespan of an individual. Therefore, assessments of nutritional status of school children are essential tools for policy makers to design appropriate intervention strategies. This study determines the pooled prevalence of undernutrition, major risk factors, and potential target regions for intervention in the country. Therefore, the result of this meta-analysis will help policy makers to evaluate the existing intervention strategies as well as to design alternative approaches to reduce undernutrition among school children in Ethiopia.

\section{Strength and limitations}

This study provides the pooled prevalence of stunting and wasting/thinness among school children in Ethiopia. The present study identifies variation of stunting and wasting/thinness 
in school children among the different regional states in Ethiopia. In addition, this study identifies major risk factors associated with stunting and wasting/thinness in Ethiopia, which are important supplement for policy makers. Despite these strengths, the study has a number of limitations. First, this meta-analysis did not include underweight among school children due to lack of consistency among the parameters used in the selected articles for this review. Second, the numbers of articles used in this study were not uniformly distributed across regions in the country. Third, the present study did not show the level of variation of stunting and wasting/thinness between sexes.

\section{Conclusions}

This study revealed that the prevalence of stunting and wasting/thinness among school children is remaining high in Ethiopia. The existing nutritional intervention strategies did not bring significant change in nutritional status of school children in the country. Therefore, there is an urgent need of design alternative intervention strategies to reduce the level of undernutrition among children in Ethiopia. The present study identifies a number of risk factors associated with stunting and wasting/thinness of school children. The identified risk factors in this review can be potential targets to design new interventions strategies by policy makers in the country.

\section{Abbreviations}

CI: Confidence Interval

$\mathrm{I}^{2}$ : Inverse Variance Index

PRISMA: Preferred Reporting Items for Systematic Reviews and Meta-analysis

SNNP: South Nations and Nationalities Peoples'

STROBE: Strengthening the Reporting of Observational Studies in Epidemiology

WHO: World Health Organization

MDG: Millennium Development Goal

NCHS: National Center for Health Statistics

SD: Standard Deviation

BMI: Body Mass Index 
STROBE: Strengthening the Reporting of Observational studies in Epidemiology

\section{Declarations}

The author declared that this review article is my original work and this manuscript is not submitted to other journals elsewhere.

Ethical approval and consent to participate

Not applicable

Consent for publication

Not applicable

Availability of data and materials

All the data are included with the manuscript.

Competing of interest

The author declared that there is no conflict of interest.

\section{Author's contribution}

$\mathrm{TH}$ involved in design and conducts the review, data analysis, interpretation of the findings, and drafts the manuscript.

\section{Funding}

Not applicable

\section{Author information}

Tamirat Hailegebriel (MSc) working as lecturer position in the department of Biology, Bahir Dar University, P.O. Box 79, Bahir Dar, Ethiopia.

\section{Acknowledgements}

Not applicable 


\section{References}

1. WHO Fact sheet on malnutrition [https://www.who.int/news-room/factsheets/detail/malnutrition/ Accessed 27August 2018]

2. WHO: Nutrition Landscape Information System (NLIS) country profile indicators: Interpretation Guide. Geneva, Switzerland: WHO; 2010.

3. WHO: Leveles and Trends in Child Malnutrition: UNICEF / WHO / World Bank Group Joint Child Malnutrition Estimates. WHO brochoure. 2017.

4. de Onis M, Borghi E, Blössner M: Levels \& Trends in Child Malnutrition Malnutrition. UNICEF-WHO-The World Bank Joint Child Malnutrition Estimates. 2011.

5. Akombi BJ, Agho KE, Hall JJ, Wali N, Renzaho AMN, Merom D: Stunting, Wasting and Underweight in Sub-Saharan Africa: A Systematic Review. Int J Environ Res Public Health 2017, 14(8):863.

6. Best C, Neufingerl N, Geel Lv, Briel Tvd, Osendarp S: The nutritional status of schoolaged children: Why should we care? Food and Nutr Bull 2010, 31(3):400-417.

7. UN: The Millennium Development Goals Report. United Nations, New York,NY, USA; 2015.

8. Webb P, Stordalen GA, Singh S, Wijesinha-Bettoni R, Shetty P, Lartey A: Hunger and malnutrition in the 21st century. BMJ 2018, 361:k2238.

9. CSA: Summary and Statistical Report of the 2007 Ethiopia Population and Housing Census Results, Central Statistical Agency. Addis Ababa; 2008.

10. Hall A, Kassa T, Demissie T, Degefie T, Lee S: National survey of the health and nutrition of schoolchildren in Ethiopia. Trop Med Int Health 2008, 13(12 ):1518-1526.

11. WHO Growth Reference data for 5-19 years [http://www.who.int/growthref/en/. Accessed 27August 2018]

12. Moher D, Liberati A, Tetzlaff J, Altman DG: Preferred reporting items for systematic reviews and meta-analyses: the PRISMA statement. BMJ 2009, 339.

13. Elm Ev, Altman DG, Egger M, Pocock SJ, Gøtzsche PC, Vandenbroucke JP: The Strengthening the Reporting of Observational Studies in Epidemiology (STROBE) 
Statement: Guidelines for Reporting Observational Studies. PLoS Med 2007, 4(10):e296. 210.1371/journal.pmed. 0040296.

14. Higgins JPT, Thompson SG, Deeks JJ, Altman DG: Measuring inconsistency in metaanalyses. BMJ 2003, 327(7414):557-560.

15. Melsen WG, Bootsma MCJ, Rovers MM, Bonten MJM: The effects of clinical and statistical heterogeneity on the predictive values of results from meta-analyses. Clinl Microbiol Infect 2014, 20(2):123-129.

16. Gebreyohannes Y, Shiferaw S, Demtsu B, Bugssa G: Nutritional status of adolescents in selected government and private secondary schools of Addis Ababa, Ethiopia. Int J Nutr Food Sci 2014, 3(6):504-514.

17. Degarege D, Degarege A, Animut A: Undernutrition and associated risk factors among school age children in Addis Ababa, Ethiopia. BMC Public Health 2015, 15(1):375.

18. Nguyen NL, Gelaye B, Aboset N, Kumie A, Williams MA, Berhane Y: Intestinal parasitic infection and nutritional status among school children in Angolela, Ethiopia. J Prev Med Hyg 2012, 53(3):157-164.

19. Hailegebriel $\mathrm{T}$ : Undernutrition, intestinal parasitic infection and associated risk factors among selected primary school children in Bahir Dar, Ethiopia. BMC Infect Dis 2018, 18(1):394.

20. Demilew YM, Emiru AA: Under nutrition and associated factors among school adolescents in Dangila Town, Northwest Ethiopia: a cross sectional study. Afr Health Sci 2018, 18(3):756-766.

21. Zelellw D, Gebreigziabher B, Alene K, Negatie B, Kasahune T: Prevalence and Associated Factors of Stunting Among Schoolchildren, in Debre Markos Town and Gozamen Woreda, East Gojjam Zone, Amhara Regional State, Ethiopia, 2013. J Nutr Food Sci 2014, S8:007.

22. Alelign T, Degarege A, Erko B: Prevalence and factors associated with undernutrition and anaemia among school children in Durbete Town, northwest Ethiopia. Archives of Public Health 2015, 73(1):34. 
23. Mekonnen H, Tadesse T, Kisi T: Malnutrition and its Correlates among Rural Primary School Children of Fogera District, Northwest Ethiopia. . J Nutr Disorders Ther 2013, S12.

24. Herrador Z, Sordo L, Gadisa E, Moreno J, Nieto J, Benito A, Aseffa A, Cañavate C, Custodio E: Cross-sectional study of malnutrition and associated factors among school aged children in rural and urban settings of Fogera and Libo Kemkem districts, Ethiopia. PLOS ONE 2014, 9(9):e105880-e105880.

25. Worku N, Erko B, Torban W, Belay M, Kassu A, Fetene T, Huruy K: Malnutrition and intestinal parasitic infections in school children of Gondar, North West Ethiopia. Ethiop Med J 2009, 47(1):9-16.

26. Amare B, Moges B, Fantahun B, Tafess K, Woldeyohannes D, Yismaw G, Ayane T, Yabutani T, Mulu A, Ota F et al: Micronutrient levels and nutritional status of school children living in Northwest Ethiopia. Nutrition Journal 2012, 11(1):108.

27. Menber Y, Tsegaye D, Woday A, Cherie H, Kebede S: Prevalence of Stunting and Associated Factors among School Age Children in Primary Schools of Haik Town, South Wollo Zone, North-Eastern Ethiopia. J Clin Cell Immunol 2018, 9(1):1000539.

28. Mazengia L, Biks A: Predictors of Stunting among School-Age Children in Northwestern Ethiopia. J Nutr Metab 2018, 2018:7.

29. Abdi M, Nibret E, Munshea A: Prevalence of intestinal helminthicinfections and malnutrition amongschoolchildren of the Zegie Peninsula,northwestern Ethiopia. $J$ Infect Public Health 2017, 10:84-92.

30. Amare B, Ali J, Moges B, Yismaw G, Belyhun Y, Gebretsadik S, Woldeyohannes D, Tafess K, Abate E, Endris M et al: Nutritional status, intestinal parasite infection and allergy among school children in Northwest Ethiopia. BMC Pediatrics 2013, 13:7-7.

31. Asmare B, Taddele M, Berihun S, Wagnew F: Nutritional status and correlation with academic performance among primary school children, northwest Ethiopia. BMC research notes 2018, 11(1):805.

32. Reji P, Belay G, Erko B, Legesse M, Belay M: Intestinal parasitic infections and malnutrition amongst first-cycle primary schoolchildren in Adama, Ethiopia. Afr J Prim 
Health Care Fam Med 2011, 3(1):198.

33. Damie T, Wondafrash M, Teklehaymanot A: Nutritional status and associated factors among school adolescent in Chiro Town, West Hararge, Ethiopia. Gaziantep Med J 2015, 21(1):32-42.

34. Mekonnen Z, Meka S, Zeynudin A, Suleman S: Schistosoma mansoni infection and undernutrition among school age children in Fincha'a sugar estate, rural part of West Ethiopia. BMC research notes 2014, 7(1):763.

35. Mesfin F, Berhane Y, Worku A: Prevalence and associated factors of stunting among primary school children in Eastern Ethiopia. Nutr Diet Suppl 2015, 7:61-68.

36. Mitiku H, Admassu D, Teklemariam Z, Weldegebreal F, Nigusse A: Nutritional status of school children in eastern Hararghe administrative zone, eastern Ethiopia. J Public Health: From Theory to Practice 2018, 27:111-118.

37. Abebe F, Geleto A, Sena L, Hailu C: Predictors of academic performance with due focus on undernutrition among students attending primary schools of Hawa Gelan district, Southwest Ethiopia: a school based cross sectional study. BMC Nutrition 2017, 3(30).

38. Awel A, Lema T, Hebo $\mathrm{H}$ : Nutritional status and associated factors among primary school adolescents of pastoral and agropastoral communities, Mieso Woreda, Somali Region, Ethiopia: A comparative cross-sectional study. J Public Health Epidemiol 2016, 8(11):297-310.

39. Hassen H, G/Aregay F, Melkie A, Gezu M, Alayu A, Kefelew T: Chronic Undernutrition and Associated Factors among School Age Children in South West Ethiopia. J Biol AgriC Health 2015, 5(21):113-122.

40. Zerdo Z, Yohanes T, Tariku B, Teshome T: Association between Nutritional Status and Soil-Transmitted Helminthes Re-Infection among School-Age Children in Chencha District, Southern Ethiopia: A Cross-Sectional Study. Transl Biomed 2017, 8(2):111.

41. Wolde M, Berhan Y, Chala A: Determinants of underweight, stunting and wasting among schoolchildren. BMC public health 2015, 15:8-8.

42. Tulu B, Taye S, Amsalu E: Prevalence and its associated risk factors of intestinal parasitic infections among Yadot primary school children of South Eastern Ethiopia: a 
cross-sectional study. BMC research notes 2014, 7:848.

43. Birmeka M, Urga K, Petros B: Intestinal Parasitic Infection and Nutritional Status of Elementary Schoolchildren Aged 7 - 14 in Enemorena-Ener District, Gurage Zone, Ethiopia. EC Nutrition 2017, 9(3):129-141.

44. Molla E, Mamo H: Soil-transmitted helminth infections, anemia and undernutrition among schoolchildren in Yirgacheffee, South Ethiopia. BMC research notes 2018, 11(1):585.

45. Tariku EZ, Abebe GA, Melketsedik ZA, Gutema BT: Prevalence and factors associated with stunting and thinness among school-age children in Arba Minch Health and Demographic Surveillance Site, Southern Ethiopia. PLoS One 2018, 13(11):e0206659e0206659.

46. Bogale TY, Bala ET, Tadesse M, Asamoah BO: Prevalence and associated factors for stunting among 6-12 years old school age children from rural community of Humbo district, Southern Ethiopia. BMC public health 2018, 18(1):653-653.

47. Grimes JET, Tadesse G, Gardiner IA, Yard E, Wuletaw Y, Templeton MR, Harrison WE, Drake LJ: Sanitation, hookworm, anemia, stunting, and wasting in primary school children in southern Ethiopia: Baseline results from a study in $\mathbf{3 0}$ schools. PLoS Negl Trop Dis 2017, 11(10):e0005948.

48. Degarege A, Erko B: Association between intestinal helminth infections and underweight among school children in Tikur Wuha Elementary School, Northwestern Ethiopia. J Inf Public Health 2013, 6(2):125-133.

49. Teferi DY, Atomssa GE, Mekonnen TC: Overweight and Undernutrition in the Cases of School-Going Adolescents in Wolaita Sodo Town, Southern Ethiopia: Cross-Sectional Study. J Nutr Metab 2018, 2018:10.

50. Weres Z, Yebyo H, Miruts K, Gesesew H, Woldehymanot T: Assessment of Adolescents' Under Nutrition Level among School Students in Eastern Tigray, Ethiopia: A CrossSectional Study. J Nutr Food Sci 2015, 5(5).

51. Zeru S, Mulugeta A, Gebretsadik T: Assessment of Nutritional Status and Other Factors Correlates with Academic Performance of Lower Primary School Children from 
Mekelle, Northern Ethiopia. Research \& Reviews: J Comp Biol 2017, 6(2):1-11.

52. Kidane E, Menkir S, Kebede A, Desta M: Prevalence of intestinal parasitic infections and their associations with anthropometric measurements of school children in selected primary schools, Wukro Town, Eastern Tigray, Ethiopia. Int J Curr Microbiol App Sci 2014, 3(3):11-29.

53. Melaku YA, Zello GA, Gill TK, Adams RJ, Shi Z: Prevalence and factors associated with stunting and thinness among adolescent students in Northern Ethiopia: a comparison to World Health Organization standards. Archives of public health 2015, 73:44-44.

54. Gebremariam H, Seid O, Assefa H: Assessment of nutritional status and associated factors among school going adolescents of Mekelle City, Northern Ethiopia. Int J Nutr Food Sci 2015, 4(1):118-124.

55. WHO: Development Initiatives, 2018 Global Nutrition Report: Shining a light to spur action on nutrition. UK; 2018.

56. Jomaa LH, McDonnell E, Probart C: School feeding programs in developing countries: impacts on children's health and educational outcomes. Nutr Rev 2011, 69(2):83-98.

57. Caleyachetty R, Thomas GN, Kengne AP, Echouffo-Tcheugui JB, Schilsky S, Khodabocus J, Uauy R: The double burden of malnutrition among adolescents: analysis of data from the Global School-Based Student Health and Health Behavior in SchoolAged Children surveys in 57 low- and middle-income countries. Am J Clin Nutr 2018, 108(2):414-424.

58. Ansuya, Nayak B, Unnikrishnan B, Ravishankar N, Shetty A, MundkurLC30-LC35 S: Malnutrition among children in karnataka: A systematic review and meta-analysis. $J$ Clin Diagn Res 2018, 12(11).

59. Yeasmin S, K KI: Prevalence and Determinants of Undernutrition among School Age Slum Children in Dhaka City, Bangladesh J Nutr Health Sci 2016, 3(2): 201.

60. Moradi S, Mirzababaei A, Mohammadi H, Moosavian SP, Arab A, Jannat B, Mirzaei K: Food Insecurity and the Risks of Under-nutrition Complications among Children and Adolescents: A Systematic Review and Meta-Analysis. Nutrition 2018. 
61. Wamani H, Åstrøm AN, Peterson S, Tumwine JK, Tylleskär T: Boys are more stunted than girls in Sub-Saharan Africa: a meta-analysis of 16 demographic and health surveys. BMC Pediatrics 2007, 7(1):17.

62. Francis L, Kirunda BE, Orach CG: Intestinal Helminth Infections and Nutritional Status of Children Attending Primary Schools in Wakiso District, Central Uganda. Int J Environ Res Public Health 2012, 9:2910-2921.

63. Telford RM, Telford RD, Olive LS, Cochrane T, Davey R: Why Are Girls Less Physically Active than Boys? Findings from the LOOK Longitudinal Study. PLoS One 2016, 11(3):e0150041-e0150041.

64. Teblick A, De Deken S, Vanderbruggen W, Vermeersch M, Teblick S, Ruymaekers M, Andries J, Colebunders R, Mmbando BP: Anthropometry and Nutritional Status of Primary School Children in a Sub-urban Region in Tanzania. Int J School Health 2017, 4(3): $\mathrm{e} 46079$.

65. Erismann S, Knoblauch AM, Diagbouga S, Odermatt P, Gerold J, Shrestha A, Tarnagda G, Savadogo B, Schindler C, Utzinger J et al: Prevalence and risk factors of undernutrition among schoolchildren in the Plateau Central and Centre-Ouest regions of Burkina Faso. Infectious Diseases of Poverty 2017, 6(17).

66. Asim M, Nawaz Y: Child Malnutrition in Pakistan: Evidence from Literature. Children 2018, 5(60).

67. Ahmed A, Al-Mekhlafi HM, Al-Adhroey AH, Ithoi I, Abdulsalam AM, Surin J: The nutritional impacts of soil-transmitted helminths infections among Orang Asli schoolchildren in rural Malaysia. Parasites \& Vectors 2012, 5(1):119.

68. Gier Bd, Ponce MC, Bor Mvd, Doak CM, Polman K: Helminth infections and micronutrients in school age children: a systematic review and meta-analysis. Am J Clin Nutr 2014, 99:1499-1509.

69. Moncayo AL, Lovato R, Cooper PJ: Soil-transmitted helminth infections and nutritional status in Ecuador: findings from a national survey and implications for control strategies. BMJ Open 2018, 8(4):e021319. 


\section{Tables}

Due to technical limitations, the tables are only available as a download in the supplemental files section

\section{Figures}
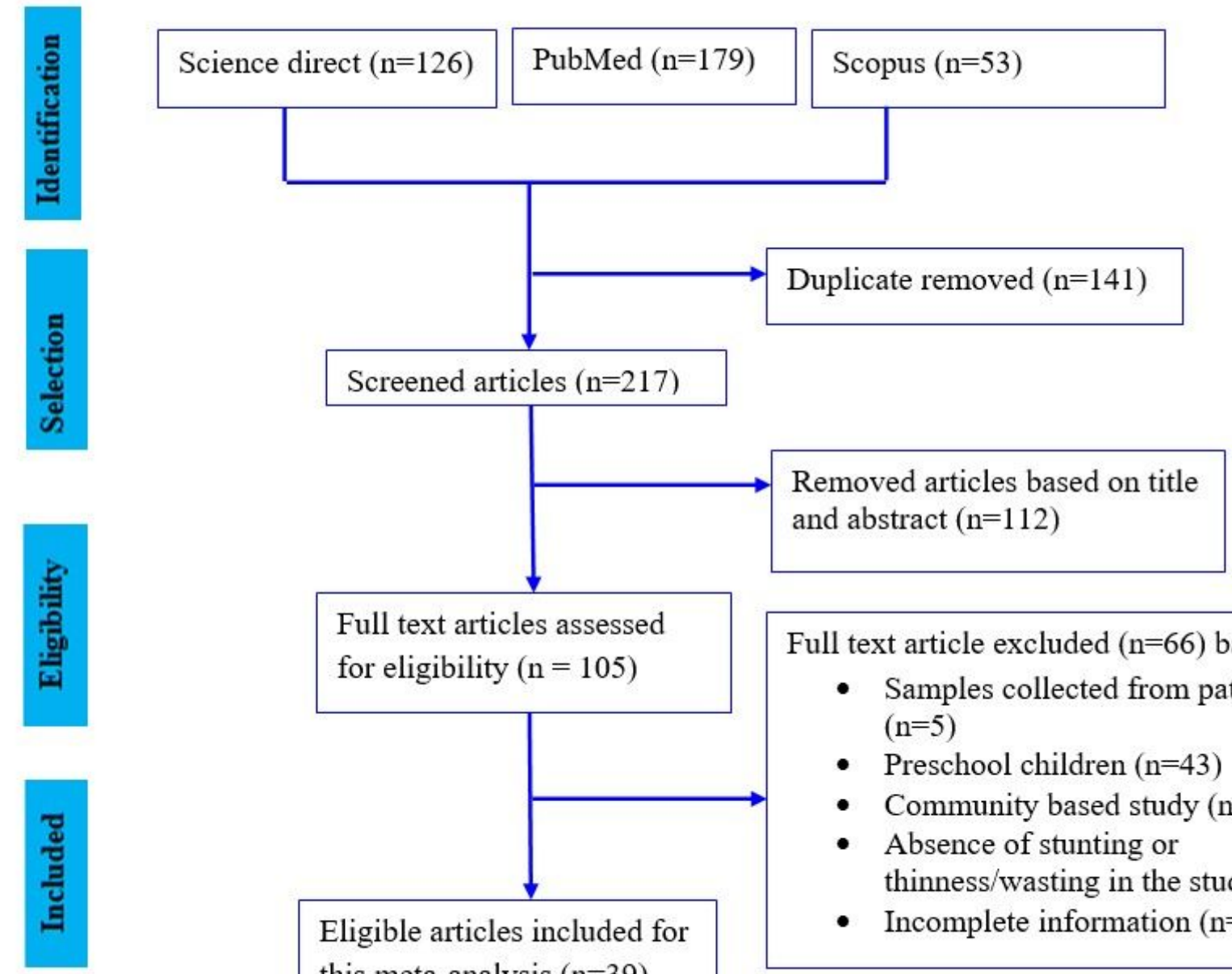

Full text articles assessed for eligibility $(n=105)$

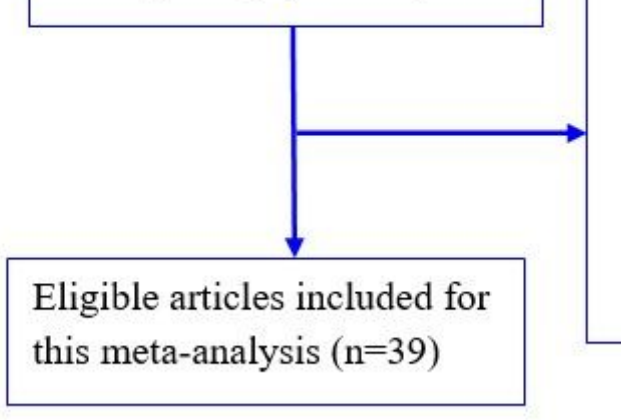

Full text article excluded $(\mathrm{n}=66)$ based on:

- Samples collected from patients $(\mathrm{n}=5)$

- Preschool children $(\mathrm{n}=43)$

- Community based study $(\mathrm{n}=11)$

- Absence of stunting or thinness/wasting in the study $(n=2)$

- Incomplete information $(n=5)$

\section{Figure 1}

PRISMA flow diagram of publications considered for the review on undernutrition (stunting and thinness/wasting) in Ethiopia 
First author (year)

ES $(96 \% \mathrm{Cl})$

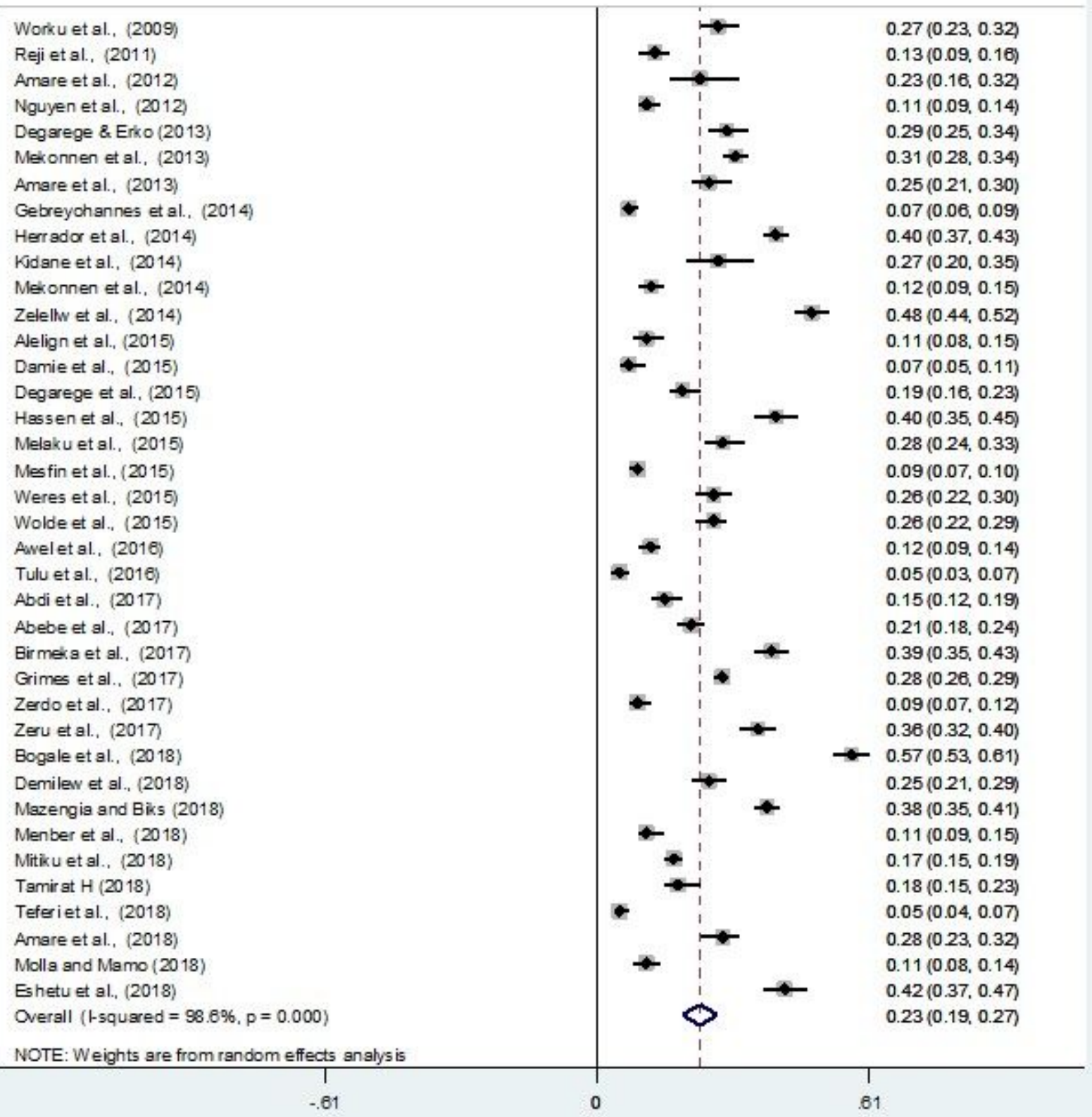

\section{Figure 2}

Forest plot for the prevalence of stunting among school children in Ethiopia. Each square represent effect size (ES) of individual studies and the horizontal line represent the $95 \% \mathrm{Cl}$. The diamond indicates the pooled effect and the vertical dash lines indicate the overall estimate. 
First author (year)

$\mathrm{ES}(96 \% \mathrm{Cl})$

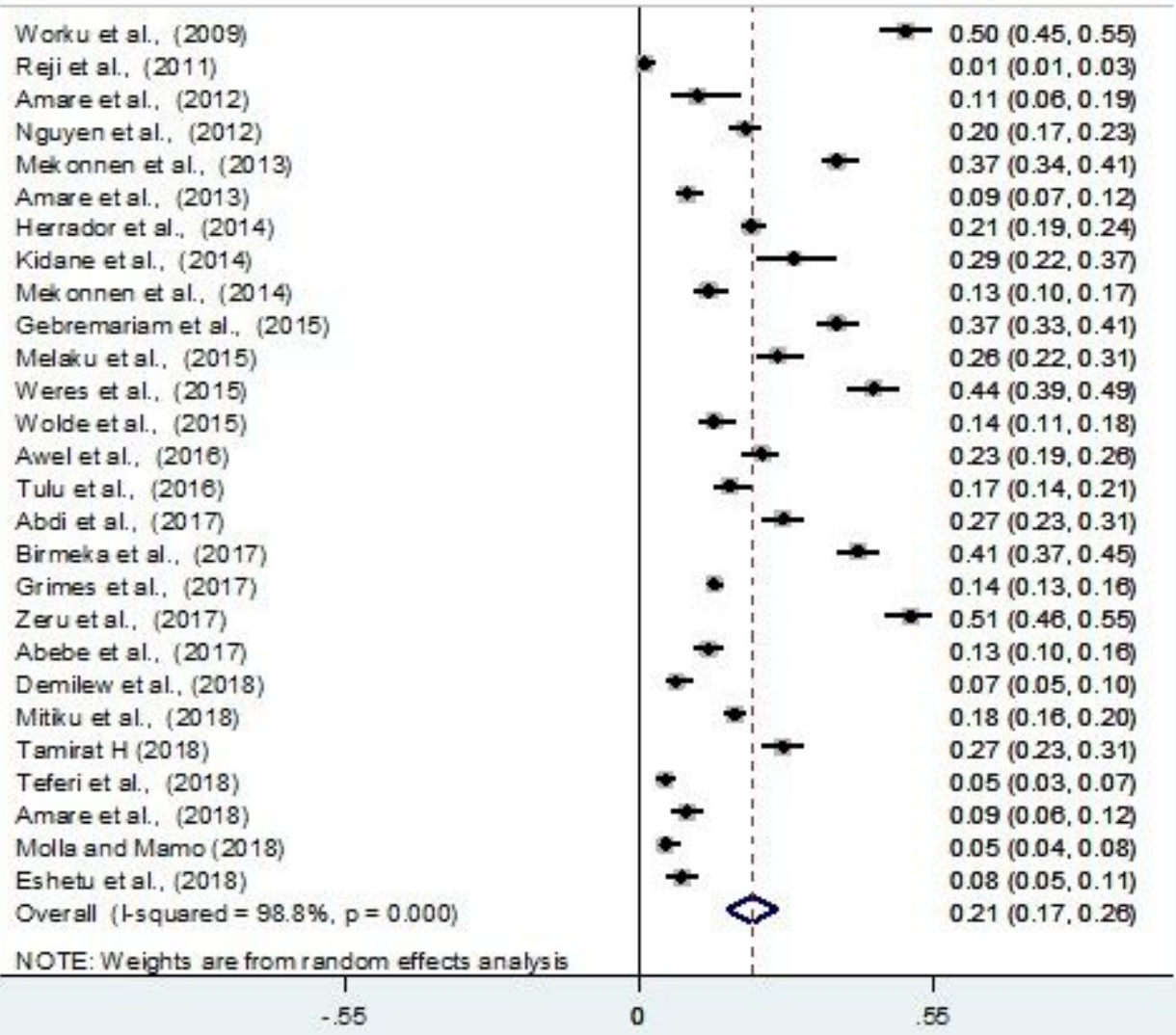

।

\section{Figure 3}

Forest plot for the prevalence of wasting/thinness among school children in Ethiopia. Each square represent effect size (ES) of individual studies and the horizontal line represent the $95 \% \mathrm{Cl}$. The diamond indicates the pooled effect and the vertical dash lines indicate the overall estimate. 

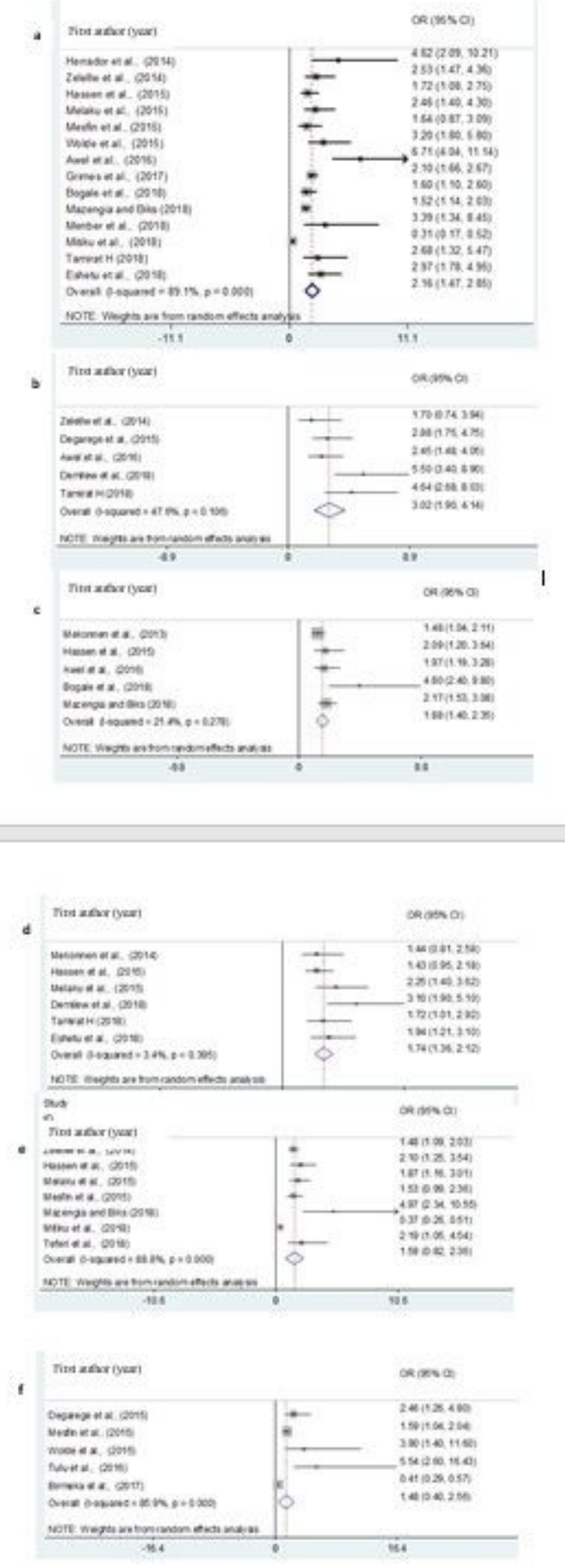

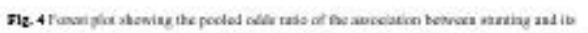

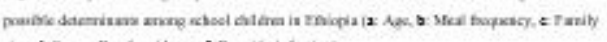

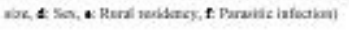

\section{Figure 4}

Forest plot showing the pooled odds ratio of the association between stunting and its possible determinants among school children in Ethiopia (a: Age, b: Meal frequency, c: Family size, d: Sex, e: Rural residency, f: Parasitic infection) 
a

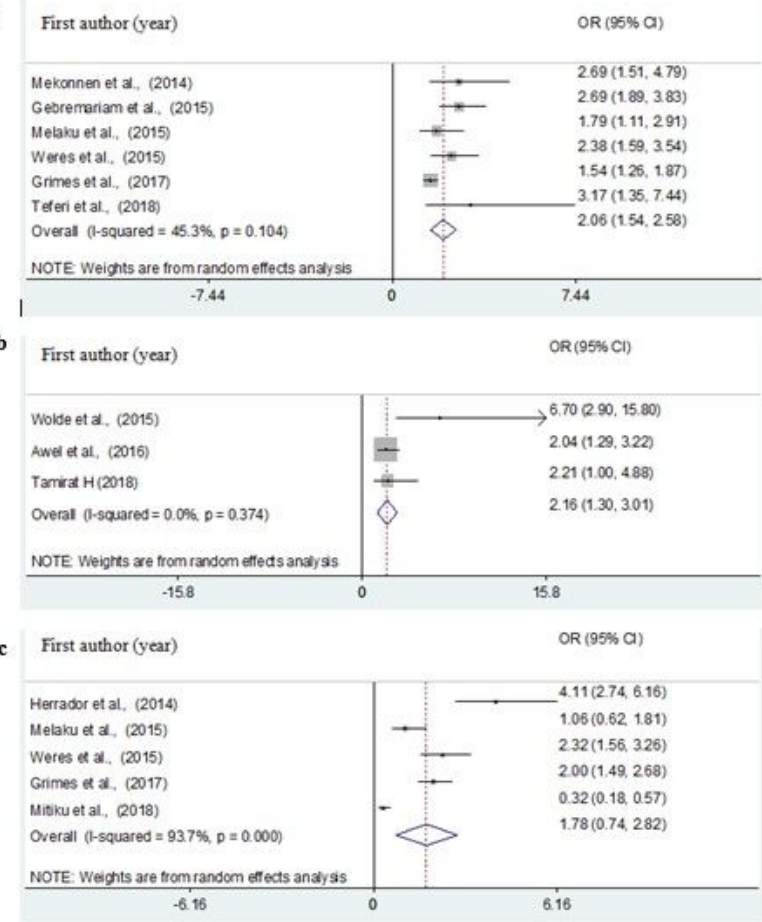

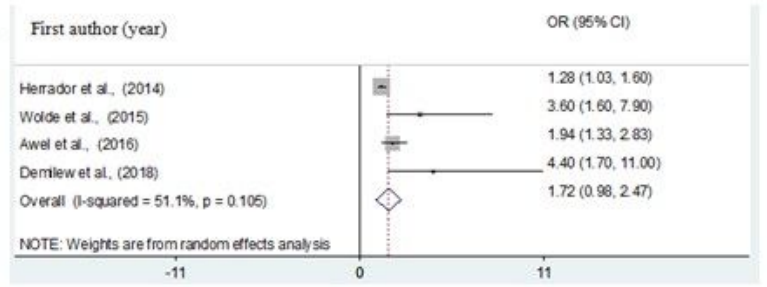

Fig, 5 Forest plot showing the pooled odds ratio of the association between wasting/thinness and its possible determinants among school children in Ethiopia (a: Sex, b: Family income, c: Age, d: Family size)

\section{Figure 5}

Forest plot showing the pooled odds ratio of the association between wasting/thinness and its possible determinants among school children in Ethiopia (a: Sex, b: Family income, c: Age, d: Family size)

\section{Supplementary Files}

This is a list of supplementary files associated with this preprint. Click to download.

- PRISMAchecklistS1table.doc

- QualityassessementS3table.doc

- Table1.doc

- QualityassessementS2table.doc

- Table3.doc

- Table2.doc 